\title{
SEGRE MALAGOLI, ENZO Y SCOTTI, SIMONA (2013). Immaginari del cambiamento in America Latina. Religioni, culture, dinamiche economico-sociali. Firenze: Mauro Pagliai Editore, 205 pp.
}

\author{
Alessandra Olivi \\ Universidad de Sevilla
}

Sondear la complejidad del universo político-social de América Latina en sus múltiples conexiones con la cuestión religiosa es el desafío que se propone este reading, fruto de las intervenciones presentadas en ocasión de la Summer School on Religions in Europe 2012. Para movernos en el vasto panorama que nos ofrece este texto utilizaremos como brújula a los recientes sucesos socio-políticos que han interesado a Paraguay, a los que nos introduce la entrevista al depuesto presidente Fernando Lugo con la que se abre esta reseña.

Paraguay es uno de los países menos conocidos de América del Sur. A principio del siglo XX, el periodista español Rafael Barrett escribía, refiriéndose a Paraguay: "En uno de mis viajes lejanos, descubrí una isla. De vuelta, visité a un célebre geógrafo. Me oyó, consultó largamente libros y planos, y me dijo: La isla que ha descubierto no existe... Este brevísimo apólogo, citado por Arnaldo Nesti en la introducción del libro, no es solamente una referencia al espacio utópico, sino, y sobre todo, una llamada de atención sobre el aislamiento geográfico y cultural que ha sufrido históricamente este país, en particular, y muchos otros de la región. Coacervo de etnias y de culturas, Paraguay, como el resto de los países de América Latina, ha sido construido por la progresiva superposición de elementos exógenos y endógenos, dando vida a una realidad fluida que se bate entre continuidad y trasformación. Gobernado por más de sesenta años 
por el conservador Partido Colorado, en marcada continuidad político-ideológica con el régimen del general Stroessner, en el año 2008 el país expresó en las urnas la voluntad de invertir su rumbo. El obispo católico Fernando Lugo, a la guía de la Alianza Patriótica para el Cambio, una coalición de más de una docena de partidos de oposición y movimientos sociales, fue elegido presidente de Paraguay en abril de 2008, asumiendo la guía del país en agosto del mismo año tras recibir la dispensa del Papa Benedicto XVI para ejercer su cargo presidencial. Durante los años de gobierno de Fernando Lugo, Paraguay registra un marcado crecimiento económico que revierte positivamente sobre el programa de reformas sociales que el gobierno impulsa en los mismos años. En junio 2012, sin embargo, tras la violenta represión policial de la protesta campesina surgida en la localidad de Curuguaty, el parlamento paraguayo aprueba la realización de un juicio político en contra del presidente de la República, alegando mal desempeño en sus funciones. Recurriendo a lo que ha sido calificado como un "golpe de Estado constitucional", Lugo es destituido del cargo de presidente. Esclarecedora, especialmente a fines de recomponer la controvertida relación entre política y religión que caracteriza a la región latinoamericana, es la posición que asume la Nunciatura Vaticana frente a estos sucesos. Mientras que la mayoría de los gobiernos latinoamericanos y algunos europeos han condenado la destitución del presidente calificándola como una "alteración del orden democrático", solamente pocas horas después de que Fernando Lugo fuera destituido, el Vaticano se apresuraba a reconocer y bendecir el gobierno ilegitimo de su sucesor, Federico Franco.

La experiencia de Paraguay, aquí someramente resumida, nos parece muy emblemática de la situación pasada y presente de la mayoría de los países de América Latina, conteniendo en germen los principales elementos recogidos en los textos que nos encaminamos a presentar. La lucha que ha habido en Paraguay entre la vía pacífica hacia un ejercicio de democracia plena y la voluntad continuista de los partidos políticos de tradición autoritaria, que encarnaran a los poderes fuertes de la oligarquía nacional respaldados por las grandes fuerzas transnacionales, hace luz sobre las posiciones contrastantes que conviven en el seno de la iglesia católica en América Latina y que se manifiestan especialmente en relación a la cuestión política y social.

Fernando Lugo pertenece a aquel sector progresista del clero católico cercano a las posiciones de la Teología de la Liberación, que tanta influencia ha tenido sobre la teología postconciliar, especialmente en América Latina que la ha visto nacer. A la figura de Gustavo Gutiérrez, sacerdote y teólogo peruano, considerado el padre intelectual de esta teología, está dedicado el artículo de Catalina Romero. Tras reseñar los principios cardinales de la Teología de la Liberación, Romero analiza la influencia que la figura de padre Gutiérrez ha tenido en la historia de Perú. Y no solamente en Perú. Valga la pena mencionar, de paso, el importante rol que han cumplido los movimientos católicos inspirados a los principios de la Teología de la Liberación en Chile en la reorganización 
de las fuerzas de base de una sociedad amedrantada y despojada de sus derechos durante los años más duros de la dictadura de Pinochet; y como nota al margen, volviendo a nuestro tema-brújula, recordaremos que el propio Fernando Lugo se formó con padre Gutiérrez, quien dirigía los cursos de verano, que se realizaban en el auditorio del Colegio de Jesús de Lima, que el futuro presidente de Paraguay frecuentó durante la década de los $70^{\prime}$ y los 80 '.

Como nos ha demostrado la experiencia de Paraguay, grande es la resistencia que encuentran las posiciones más progresistas al interior de la Iglesia Católica. A tal propósito, Peter Antes nos propone una revisión histórica de las principales críticas que ha recibido formalmente la doctrina de la Teología de la Liberación por parte de la Iglesia Católica. En primera instancia, fue Juan Pablo II quien durante su viaje apostólico en México en 1979 declaró que "la concepción de Cristo como político, revolucionario, como el subversivo de Nazaret, no está en armonía con la catequesis de la Iglesia”. Le hará eco, años después, la Conferencia Episcopal alemana que criticará especialmente el concepto marxista de liberación promovido por la Teología de la Liberación, lo que según el autor es sintomático del respaldo ideológico que la iglesia católica alemana ofrecía en ese entonces a la República Federal Alemana en su antagonismo con la socialista República Democrática.

A la colusión entre la iglesia católica y los poderes hegemónicos se puede atribuir parte de la responsabilidad por la deriva protestante que ha tenido la religiosidad en América Latina en los últimos treinta años. El creciente distanciamiento de la iglesia católica de la población más vulnerable del continente, inversamente proporcional a la cercanía con los poderes fuertes, ha preparado el terreno para la difusión de nuevas doctrinas religiosas. Demostrándose más atentas a la dimensión afectiva y comunitaria, estas doctrinas han sido capaces de ofrecerse como guías frente a la desorientación y a la pérdida de referentes interpretativos a los que se encuentran expuestos especialmente los más pobres por efecto de la brutal restructuración neoliberal impuesta a las economías latinoamericanas. Varias son las contribuciones recogidas en este texto que buscan recomponer un cuadro de conjunto de la dimensión actual del pluralismo religioso en América Latina. El artículo de Alessandro Cannariato reconstruye el origen y el desarrollo de los cultos pentecostales en la región de Chiapas, México, mientras que al pentecostalismo brasileño es dedicado el artículo de Carlo Nardella, analizando como son empleadas las técnicas propias del marketing para fomentar el proceso de evangelización de la población.

La Iglesia Católica no solamente se ha alejado de la base de la sociedad, sino que tampoco ha sido capaz de comprender el importante proceso de movilidad social que se está registrando en muchos países de América Latina. Esto ha conllevado a una progresiva de-institucionalización y de-reglamentación de la doctrina católica por mano de grupos religiosos en búsqueda del reconocimiento de su propia especificidad socio-económica y cultural. Es este el caso del movimiento carismático en Argentina, integrado, en su 
vertiente católica, sobre todo por personas de clase media -del que nos habla Verónica Roldán-, y de la Iglesia Católica Tradicional de la Ermita, secta fundamentalista del Estado de Michoacán, en México, que ocupa el artículo que nos presenta Francesco Gervasi. Nos parece, sin embargo, que el aporte más interesante que proviene de esta recopilación de ensayos consiste en el esfuerzo para superar el enfoque del mestizaje y del sincretismo con los que se ha abordado tradicionalmente el estudio de las múltiples realidades socioculturales latinoamericanas, especialmente en lo que concierne a la cuestión religiosa. Aquí la temática de las conexiones, en el sentido propuesto por Amselle (2001) -con las raíces históricas, con los repertorios culturales, políticos, económicos y religiosos, endógenos y exógenos- es utilizada como herramienta para comprender los ejercicios de reflexividad que han llevado a la definición de experiencias políticas emancipadoras y a la reafirmación y redefinición de atributos y principios propios de las culturas originarias que habían sido expulsados de la historia oficial.

El análisis de la transformación del candomblé en Brasil y de su difusión en Italia, que nos propone Barbara Ronco, formula una interesante crítica del enfoque del sincretismo como herramienta interpretativa de los fenómenos religiosos. Por otro lado, Isidoro Moreno nos recuerda la importancia de la reflexividad como vía para adoptar aquella perspectiva "desde el Sur" que nos permite acceder a comprender y valorar universos de significados alternativos, como la filosofía andina del buen vivir (sumak kawsay).

No solamente la mayoría de los gobiernos de América Latina y la Iglesia Católica más conservadora no tienen la voluntad de reconocer la profunda diversidad -política, social, cultural, religiosa- que vertebra la sociedad latinoamericana contemporánea, como nos recuerdan Enzo Segre y Mauro Castagnaro. También la propia Iglesia progresista parece incapaz de superar sus esquemas del pasado reorientado sus principios hacia la complejidad y pluralidad de las sociedades actuales. Es esta la crítica que Hans Gutiérrez mueve a la Teología de la Liberación, alentando la búsqueda de un camino hacia la integración como medida para mantener la tensión creativa entre las varias ánimas de América Latina, evitando contraposiciones paralizantes y polarizantes. Asimismo, para que la Teología de la Liberación siga cumpliendo con su proceso de de-fetichización de las narrativas hegemónicas contemporáneas es necesario un mayor reconocimiento e integración de los aportes provenientes de la teología feminista, de la teología ecologista, de la de matriz afro-latinoamericana, entre otras, como emerge de los textos de Luis Martínez Andrade y Claudia Fanti.

La polifonía de las voces contenidas en este texto, y solo parcialmente exploradas en esta breve reseña, contribuyen a penetrar las primeras capas de la complejidad que caracteriza a la hodierna realidad latinoamericana, ofreciendo a quienquiera aproximarse al estudio de la cuestión religiosa en América Latina un interesante y diverso bagaje de herramientas críticas.

Retomando las palabras de Fernando Lugo, este texto es en definitiva un llamado a que 
las ciencias sociales contribuyan a la búsqueda de un nuevo paradigma de Estado, no solamente eficiente y capaz de responder a las necesidades de la población latinoamericana frente a los desafíos globales, sino capaz de convivir con otras instituciones y reconocer los múltiples valores culturales y religiosos que dan todavía un significado humano a la convivencia entre las personas.

\section{REFERENCIAS BILIOGRÁFICAS}

Amselle, Jean-Loup (2001) Branchements. Anthropologie de l'universalité des cultures. Paris: Flammarion. 